\title{
Effect of Fiber Length on Processing and Properties of Extruded Wood-Fiber/HDPE Composites
}

\author{
Sébastien Migneault, ${ }^{1}$ Ahmed Koubaa, ${ }^{2}$ Fouad Erchiqui, ${ }^{2}$ Abdelkader Chaala, ${ }^{3}$ \\ Karl Englund, Cornelia Krause, ${ }^{5}$ Michael Wolcott ${ }^{4}$ \\ ${ }^{1}$ Centre de Recherche sur le Bois (CRB), Université Laval, Québec, Canada \\ ${ }^{2}$ Université du Québec en Abitibi-Témiscamingue (UQAT), Rouyn-Noranda, Québec, Canada \\ ${ }^{3}$ Service de Recherche et D'expertise en Transformation des Produits Forestiers, Québec, Canada \\ ${ }_{5}^{4}$ Wood Materials and Engineering Laboratory, Washington State University (WSU) \\ ${ }^{5}$ Université du Québec à Chicoutimi (UQAC), Chicoutimi, Québec, Canada
}

Received 29 January 2008; accepted 11 May 2008

DOI 10.1002/app. 28720

Published online 10 July 2008 in Wiley InterScience (www.interscience.wiley.com).

\begin{abstract}
Fiber length and distribution play important roles in the processing and mechanical performance of fiber-based products such as paper and fiberboard. In the case of wood-plastic composites (WPC), the production of WPC with long fibers has been neglected, because they are difficult to handle with current production equipment. This study provides a better understanding of the effect of fiber length on WPC processing and properties. The objectives of this study were therefore to determine the role of fiber length in the formation process and property development of WPC. Three chemithermomechanical pulps (CTMP) with different lengths, distributions, and length-to-diameter ratios $(L / D)$ were obtained by mechanical refining. Length, shape, and distribution were characterized using a fiber quality analyzer (FQA). The
\end{abstract}

rheometer torque properties of high-density polyethylene (HDPE) filled with the pulps at different loads were studied. Variations in fiber load and length distribution resulted in significant variations in melting properties and torque characteristics. Composites from the three length distributions were successfully processed using extrusion. Physical and mechanical properties of the obtained composites varied with both length distribution and additive type. Mechanical properties increased with increasing fiber length, whereas performance in water immersion tests decreased. (O 2008 Wiley Periodicals, Inc. J Appl Polym Sci 110: 1085-1092, 2008

Key words: wood-plastic composite; high density polyethylene; fiber length; extrusion; torque rheometer

\section{INTRODUCTION}

In the recent years, there has been much interest in the development of wood-plastic composites (WPC) for use as building materials due to the abundance, low cost, and processability of wood as a filler. ${ }^{1-3}$ One reason that this fairly new material class has outperformed competing plastic products in decking applications is that the addition of wood filler is an effective way to increase product stiffness, although strength usually suffers. ${ }^{4,5}$ Commercial WPC is generally produced from wood flour, with a low lengthto-diameter $(L / D)$ ratio. For example, commercial pine flour particles have $L / D$ ratios ranging from 3.3 to $4.5{ }^{6}$ Although such small particle sizes integrate well into extrusion processes, low $L / D$ ratios cause

Correspondence to: A. Koubaa (ahmed.koubaa@uqat.ca).

Contract grant sponsors: Canada Research Chair Program, Ministère du développement économique et de l'Innovation du Québec (MDEIE), Natural Sciences and Engineering Research Council of Canada (NSERC), Caisse Populaire DesJardins, Tembec, UQAT foundation.

Journal of Applied Polymer Science, Vol. 110, 1085-1092 (2008) (c) 2008 Wiley Periodicals, Inc. stress concentrations leading to decreased strength compared to neat polymer. Both strength and stiffness increases can be realized with increasing fiber length if (1) adhesion between wood fibers and the plastic matrix is good; (2) fibers are uniformly dispersed in the matrix; and (3) fibers are adequately oriented. ${ }^{5,7}$ However, when using wood fibers without effective dispersion or coupling agents, the benefits of mechanical properties are negated. ${ }^{5,7}$

Julson et al. ${ }^{8}$ studied the mechanical properties of WPC made with different loads and sizes of pine flour in a HDPE matrix using an injection-molding process. Compared to fiber proportion, size of screened particles showed no significant impact on mechanical properties of the composite materials. Stark and Rowlands ${ }^{6}$ compared the effect of softwood flour particles and hardwood fibers on strength properties of WPC made with polypropylene in a mold-injection process. They concluded that it is not the particle length that affects strength properties, but rather the $L / D$ value. Strength and rigidity of composites increased with increasing $L / D$ ratio. Sanschagrin et al. ${ }^{9}$ reached the same conclusion for injection-molded WPC made with CTMP 
aspen fibers having $L / D$ ratios ranging from 5 to 25 . Likewise, Lee et al. ${ }^{10}$ concluded that increasing fiber length improved WPC mechanical properties made with different types of TMP fibers at four lengths ranging from 1.74 to $3.23 \mathrm{~mm}$ in a compressionmolding process.

In terms of processing, Yam et al. ${ }^{11}$ suggested that mechanical properties and fiber length are sensitive to extrusion parameters such as screw configuration and compounding temperature. Short fibers resulted in better mechanical properties than long fibers, because they were easier to disperse in the HDPE matrix, as reported previously. ${ }^{12}$ Le Baillif and Oks$\operatorname{man}^{13}$ suggested that two extrusions improved fiber dispersion in the matrix but considerably reduced fiber length. However, tensile properties were affected by neither dispersion nor fiber length.

The melt flow behavior of wood-thermoplastic blends is often an important parameter in industrial processes such as injection molding and extrusion. ${ }^{14}$ Although it is possible to study the rheological properties of wood-filled thermoplastic composites using a torque rheometer, ${ }^{14-16}$ this technique has not been extensively used. ${ }^{17}$ The torque rheometer simulates real-life processing conditions as found in internal production extruders. By measuring the torque at the mixer shaft, the torque rheometer allows characterizing the rheological changes of the wood-plastic blend during each melting and mixing step. The sample's resistance to mixing is proportional to its viscosity. Miniature, complex-shaped electrically heated internal mixer sensors provide optimal mixing of all heterogeneous components. ${ }^{18}$ Matuana and $\mathrm{Kim}^{17}$ studied the fusion characteristics of wood flour-polyvinyl chloride blends using a torque rheometer at $180^{\circ} \mathrm{C}$ and a rotor speed of 50 rotations per minute (RPM). Finer particles (60 mesh) appeared to process more easily than coarse ones (20 mesh), and blend viscosity increased with the increasing wood load. Fusion characteristics were also found to be a function of wood species. Similarly, Li et al. ${ }^{14}$ studied the melting behavior of wood flour-plastic blends using torque rheometry and also found that blend viscosity increases with increasing fiber load. Other techniques can be used to characterize rheological properties of wood-plastic blends. Li and Wolcott ${ }^{19}$ used capillary rheometry to study the melt behavior of HDPE filled with different loads and commercial wood particle size grades. Wood particle size grades showed less significant changes in viscosity than wood content.

Wood fibers might lead to better WPC mechanical properties than wood flour. However, the use of such fibers involves several processing challenges, such as (1) difficulty feeding the production equipment with fibers due to low density ${ }^{13}$; (2) potential degradation of fibers due to processes such as extru- sion $^{11}$; and (3) tendency for fibers to agglomerate in the dry mix, resulting in poor fiber dispersion in the matrix. Consequently, the benefits of fiber length on mechanical properties are reduced..$^{5,920,21}$ Few reports have shown that using long fibers increases the mechanical properties of injection-molded WPC, ${ }^{6,9,10}$ whereas other studies have reported limited effect (or no effect) of fiber length for extruded WPC. ${ }^{11,13}$ However, with the exception of Sanschagrin et al., ${ }^{10}$ these studies used different types of fibers to vary fiber length. The effect of fiber length on WPC mechanical properties is therefore not fully understood. Moreover, there is no information in the literature on the effect of fiber length on the melting behavior of wood fiber-filled thermoplastics. There is also very little information on the effect of fiber length on the physical properties of WPC.

To better understand the impact of fiber length on WPC processing and property development, torque rheometry properties, and strength development of three different length distributions in high-density polyethylene (HDPE) were determined. The objectives of this study were (1) to determine how varying fiber lengths and proportions affect mixing and melting times of wood fibers in HDPE, and to determine the mechanical energy required to melt and mix these fibers in the polymer; and (2) to study how varying fiber lengths and proportions affect the physical and mechanical property development of WPC.

\section{EXPERIMENTAL}

White birch CTMP pulp fibers supplied by Tembec were used in this study. Three fiber length classes (long, medium, and short) were obtained by mechanical refining with a Thomas Model 4 Wiley mill. Fiber length and distribution were measured using an OPTEST fiber quality analyzer (FQA). Each length distribution was obtained from five samples of 5000 fibers each. Table I summarizes the properties of the fiber classes. Differences in the distribution of the three classes are shown in Figure 1.

HDPE LB 0100-00 (Equistar) was used as a matrix. This polymer has a melt index of $0.3 \mathrm{~g} / 10 \mathrm{~min}$, solid density of $953 \mathrm{~kg} / \mathrm{m}^{3}$, tensile strength at break of $27.3 \mathrm{MPa}$, and flexural modulus of elasticity (MOE) of 1.276 GPa. A maleated polyethylene (MAPE) AC575-A (Honeywell) was used as coupling agent, and an OptiPak OP-100 (Honeywell) was used as lubricant.

A Haake Polylab torque rheometer with a Rheomix 600p counter-rotating twin-screw mixing chamber was used to mix the CTMP fibers in HDPE, whereas measuring the torque at each blending step. Mixers had a speed ratio of $3: 2$, and temperature was regulated by electric heating and air cooling. All 

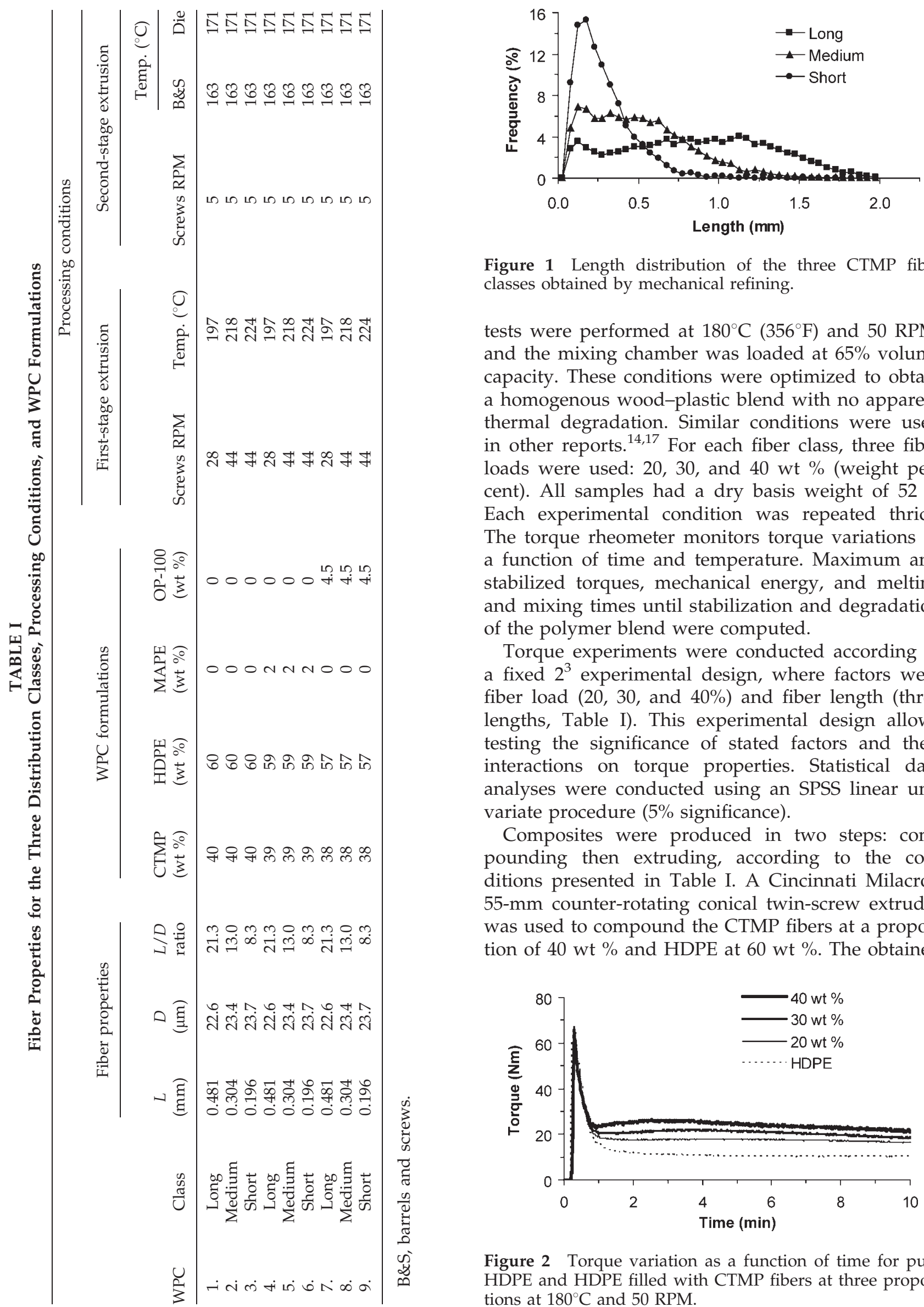

Figure 1 Length distribution of the three CTMP fiber classes obtained by mechanical refining.

tests were performed at $180^{\circ} \mathrm{C}\left(356^{\circ} \mathrm{F}\right)$ and $50 \mathrm{RPM}$, and the mixing chamber was loaded at $65 \%$ volume capacity. These conditions were optimized to obtain a homogenous wood-plastic blend with no apparent thermal degradation. Similar conditions were used in other reports. ${ }^{14,17}$ For each fiber class, three fiber loads were used: 20,30 , and $40 \mathrm{wt} \%$ (weight percent). All samples had a dry basis weight of $52 \mathrm{~g}$. Each experimental condition was repeated thrice. The torque rheometer monitors torque variations as a function of time and temperature. Maximum and stabilized torques, mechanical energy, and melting and mixing times until stabilization and degradation of the polymer blend were computed.

Torque experiments were conducted according to a fixed $2^{3}$ experimental design, where factors were fiber load (20,30, and 40\%) and fiber length (three lengths, Table I). This experimental design allows testing the significance of stated factors and their interactions on torque properties. Statistical data analyses were conducted using an SPSS linear univariate procedure ( $5 \%$ significance).

Composites were produced in two steps: compounding then extruding, according to the conditions presented in Table I. A Cincinnati Milacron 55-mm counter-rotating conical twin-screw extruder was used to compound the CTMP fibers at a proportion of $40 \mathrm{wt} \%$ and HDPE at $60 \mathrm{wt} \%$. The obtained

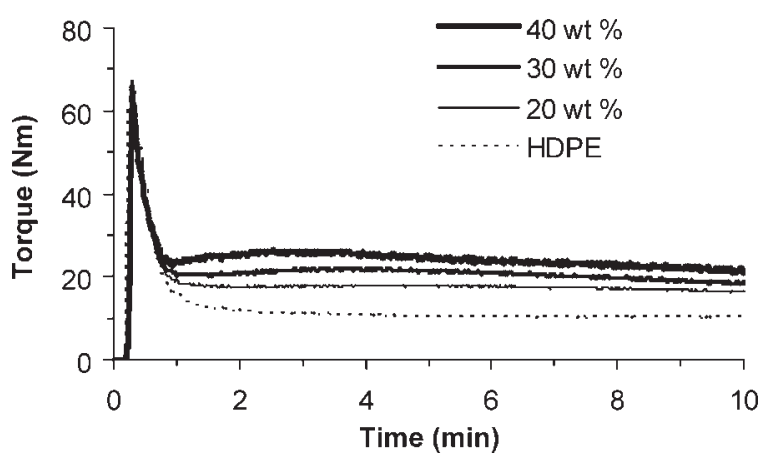

Figure 2 Torque variation as a function of time for pure HDPE and HDPE filled with CTMP fibers at three proportions at $180^{\circ} \mathrm{C}$ and $50 \mathrm{RPM}$. 


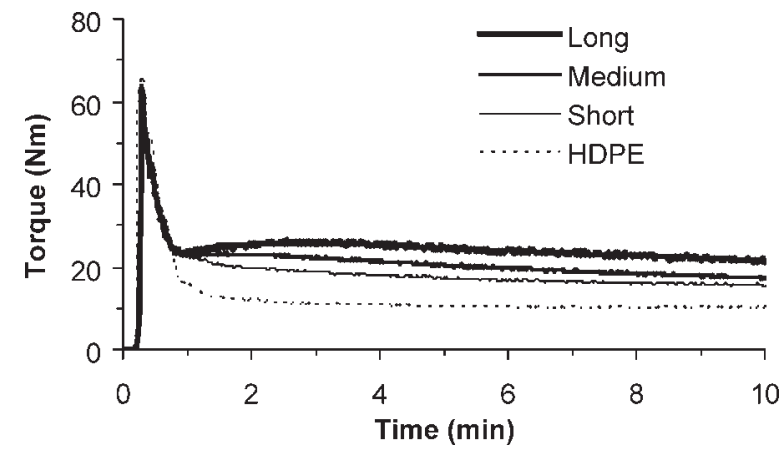

Figure 3 Torque variation as a function of time for pure HDPE and HDPE filled with 40 wt \% CTMP fibers of different lengths at $180^{\circ} \mathrm{C}$ and $50 \mathrm{RPM}$.

compound was then air cooled and ground with a Nelmor rotary knife grinder equipped with a screen having 9.6-mm diameter openings to form WPC pellets. The die was removed in a first step to reduce pressure, shear stress, and residence time of the wood fibers in the extruder and consequently to reduce fiber degradation. Temperature and RPM speed were adjusted according to fiber length to obtain a homogenous extrudate with no apparent thermal degradation. These processing conditions were optimized starting from previously determined conditions in torque rheometry tests. ${ }^{17}$

In the next step, compounded pellets were mixed with the additives in a drum blender for $10 \mathrm{~min}$, and a final extrusion was run to produce the WPC formulations, as presented in Table I. A Cincinnati Milacron 35-mm counter-rotating conical twin-screw extruder with a die having $9.53-\mathrm{mm}$ height by 38.1 $\mathrm{mm}$ width was used. After leaving the die, the extruded composite material was cooled by water jets. For all formulations, extrusion parameters were kept constant at $163^{\circ} \mathrm{C}\left(325^{\circ} \mathrm{F}\right)$ for the barrels and screws and $171^{\circ} \mathrm{C}\left(340^{\circ} \mathrm{F}\right)$ for the die. A screw speed of $5 \mathrm{RPM}$ and a vacuum of $-300 \mathrm{kPa}$ were used for
TABLE II

Results of the Analysis of Variance ( $F$ values) for Torque Properties

\begin{tabular}{lcccc}
\hline $\begin{array}{l}\text { Source of } \\
\text { variation }\end{array}$ & $\begin{array}{c}\text { Stabilized } \\
\text { torque }\end{array}$ & $\begin{array}{c}\text { Maximum } \\
\text { torque }\end{array}$ & $\begin{array}{c}\text { Mechanical } \\
\text { energy }\end{array}$ & Temperature \\
\hline $\begin{array}{l}\text { Proportion } \\
\text { Class }\end{array}$ & $50.99^{\mathrm{a}}$ & $1.83^{\mathrm{b}}$ & $38.58^{\mathrm{a}}$ & $29.02^{\mathrm{a}}$ \\
$\begin{array}{l}\text { Proportion } \times \\
\text { class }\end{array}$ & $91.66^{\mathrm{a}}$ & $6.42^{\mathrm{a}}$ & $36.46^{\mathrm{a}}$ & $17.14^{\mathrm{a}}$ \\
\hline
\end{tabular}

a Significant at 0.01 significance level.

b Not significant at 0.05 significance level.

all composites. A slow RPM was used to reduce fiber rupture.

Extrusion experiments were conducted according to a fixed factorial design. Factors were fiber length (three levels, Table I), MAPE proportion (two levels, 0 and $2 \%$ ), and lubricant proportion (two levels, 0 and $4.5 \%$ ). This experimental design allows an evaluation of the effects of fiber length, lubricant, and MAPE contents on the physical and mechanical properties of extruded WPC. Statistical analyses were also conducted using an SPSS linear univariate procedure (5\% significance). The Waller-Duncan test was used for multiple comparisons between means of all experimental conditions.

For physical testing, samples were cut with a band saw and sanded with an ISO P120 grit size sandpaper (125 $\mu \mathrm{m}$ particle size). For mechanical testing, samples were machined using a milling machine with an end mill. Tensile and three-point bending properties were measured with a Zwick/ Roel Z020 screw-powered universal materials testing machine according to ASTM D 638-03 and ASTM D 790-03, respectively. Notched Izod Impact strength tests were run with an impact tester (Testing Machines, No. 43-01), according to ASTM D 256-05. Water absorption and volume swelling were

TABLE III

Average and Standard Deviation (Between Parentheses) of Rheological Properties of HDPE Filled with CTMP Fibers Having Different Lengths and Proportions measured with a torque rheometer at $180^{\circ} \mathrm{C}$ and $50 \mathrm{RPM}$

\begin{tabular}{|c|c|c|c|c|c|}
\hline $\begin{array}{c}\text { Fiber } \\
\text { load (wt \%) }\end{array}$ & $\begin{array}{l}\text { Length } \\
\text { class }\end{array}$ & $\begin{array}{c}\text { Stabilized } \\
\text { torque }(\mathrm{Nm})^{\mathrm{a}}\end{array}$ & $\begin{array}{l}\text { Maximum } \\
\text { torque }(\mathrm{Nm})\end{array}$ & $\begin{array}{l}\text { Mechanical } \\
\text { energy }(\mathrm{kJ})^{\mathrm{a}}\end{array}$ & $\begin{array}{c}\text { Measured } \\
\text { temperature }\end{array}$ \\
\hline 0 & - & 10.2 & 66.3 & 38.3 & 184 \\
\hline \multirow[t]{3}{*}{20} & Long & $16.3 \mathrm{~cd}^{\mathrm{b}}(0.4)$ & 65.5ab (2.5) & $58.0 \mathrm{bc}(1.2)$ & $195 \mathrm{bc}(0.5)$ \\
\hline & Medium & $15.1 b(0.3)$ & 65.9ab (1.3) & $54.7 \mathrm{~b}(1.0)$ & $192 \mathrm{ab}(0.3)$ \\
\hline & Short & 13.6a (0.6) & 60.6a (1.2) & 49.8a (1.8) & 190a (0.8) \\
\hline \multirow[t]{3}{*}{30} & Long & $18.5 \mathrm{e}(0.3)$ & $67.1 b(6.0)$ & 66.7e (1.1) & $199 \mathrm{ef}(0.3)$ \\
\hline & Medium & $16.5 \mathrm{~cd}(1.4)$ & 66.0ab (1.6) & 61.7cd (7.0) & $196 c(1.8)$ \\
\hline & Short & $15.2 b(0.4)$ & 62.0ab (3.0) & $56.5 b(1.0)$ & $194 b c(0.5)$ \\
\hline \multirow[t]{3}{*}{40} & Long & $21.3 f(0.1)$ & 63.0ab (2.6) & 76.7f (1.7) & 201f (0.9) \\
\hline & Medium & $17.1 \mathrm{~d}(0.7)$ & 63.8ab (1.0) & 65.7de (4.6) & 199ef (1.3) \\
\hline & Short & $15.5 b c(0.6)$ & 61.0a (1.6) & $58.1 \mathrm{bc}(1.8)$ & $197 \mathrm{~cd}(0.8)$ \\
\hline
\end{tabular}

${ }^{\text {a }}$ Values at $10 \mathrm{~min}$.

${ }^{b}$ Means followed by the same letter are not statistically different at $95 \%$ probability level. 


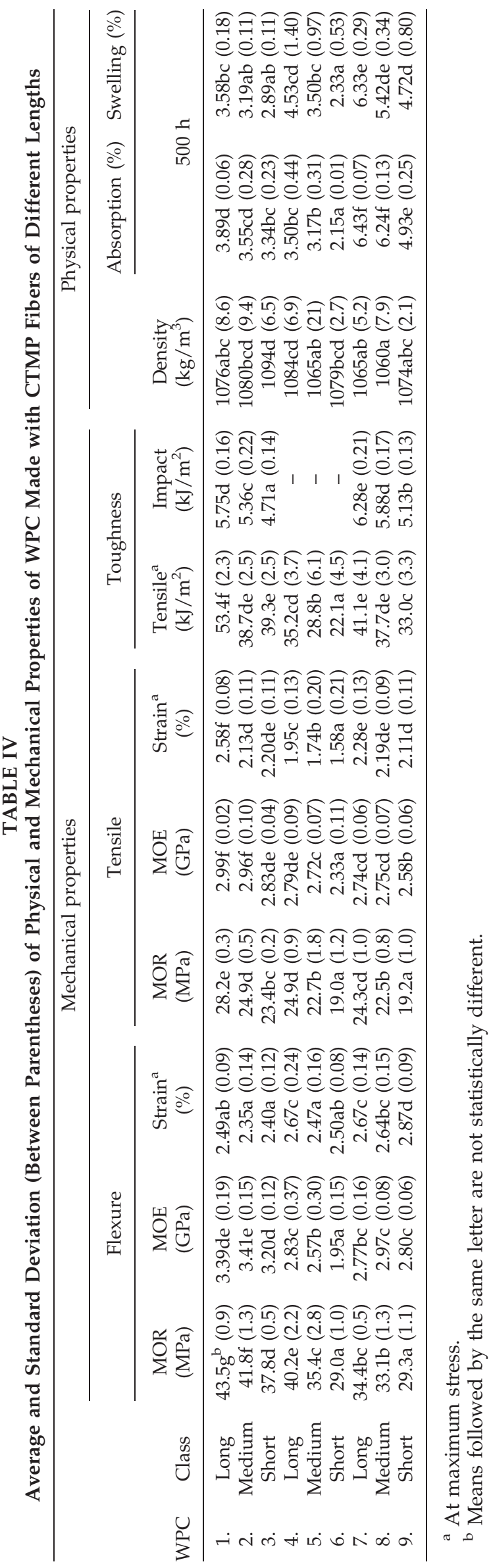

measured by weighing and measuring WPC samples submerged in water at various time intervals according to ASTM D 1037-99. Finally, solid composite density was measured according to ASTM D 2395-97.

\section{RESULTS AND DISCUSSION}

Torque properties of the wood-plastic blends varied with fiber load and length, as shown in Figures 2 and 3 , respectively. In good agreement with previous findings, ${ }^{14,16}$ adding CTMP pulp fibers to the polymer increased stabilized torque and mechanical energy. The effect of fiber length was highly significant on all reported torque properties (Table II). In agreement with the previous findings, ${ }^{17}$ mechanical energy and stabilized torque significantly increased with increasing fiber length and fiber load (Table III). Maximum torque showed no significant variation with fiber load, but varied with fiber length (Table II). However, within each fiber load, means of maximum torque were not statistically different. As expected, increase in mixing mechanical energy was accompanied by the increase in temperature (Table III).

Results show that using different fiber proportions and lengths have an important effect throughout the WPC manufacturing processes. Short fibers were the easiest to mix with HDPE, because they provided lower stabilized torque, mechanical energies, and maximum torque. Thus, the processing parameters of wood fibers and plastic blends, such as in the extrusion process, vary depending on fiber morphology and proportion. Consequently, RPM and temperature had to be adjusted for fiber length class in the pelletizing step (Table I). Yam et al. ${ }^{11}$ also found relationships between fiber length and extrusion processing parameters. The die was removed in a first step to reduce pressure, shear stress, and residence time of the wood fibers in the extruder and consequently to reduce fiber degradation.

The variations in WPC physical and mechanical properties as a function of fiber length and additives are shown in Table IV. The analysis of variance (Table V) tested the statistical significance of fiber length, MAPE, and lubricant on the physical and mechanical properties of WPC.

Adding wood fibers to HDPE slightly increased its density. This was expected, because cell density (about $1500 \mathrm{~kg} / \mathrm{m}^{3}$ ) is much higher than HDPE density (about $950 \mathrm{~kg} / \mathrm{m}^{3}$ ) and is in accordance with previous reports. ${ }^{2,22}$ Results of the analysis of variance indicate that fiber length has a significant effect on WPC density (Table V). For WPC-containing wood and plastic only, and for formulations with OP-100 lubricant, the use of the lower fiber length class resulted in slightly higher WPC density. This could be explained by the fact that longer fibers 
TABLE V

Results of the Analysis of Variance (ANOVA) for Physical and Mechanical Properties of WPC

\begin{tabular}{|c|c|c|c|c|c|c|c|c|c|c|c|}
\hline & \multicolumn{3}{|c|}{ Physical properties } & \multicolumn{8}{|c|}{ Mechanical properties } \\
\hline & \multirow[b]{2}{*}{ Density } & \multirow{2}{*}{$\frac{\text { Absorption }}{1500}$} & \multirow[t]{2}{*}{ Swelling } & \multicolumn{3}{|c|}{ Tensile } & \multicolumn{3}{|c|}{ Flexure } & \multicolumn{2}{|c|}{ Toughness } \\
\hline & & & & $E$ & $\sigma$ & $\varepsilon$ & $E$ & $\sigma$ & $\varepsilon$ & Tensile & Impact \\
\hline Length & $5.0^{\mathrm{a}}$ & $31.7^{\mathrm{b}}$ & $10.2^{\mathrm{b}}$ & $75.5^{\mathrm{b}}$ & $99.27^{\mathrm{b}}$ & $11.8^{b}$ & $17.2^{\mathrm{b}}$ & $94.2^{\mathrm{b}}$ & $3.8^{\mathrm{a}}$ & $23.9^{b}$ & $6.2^{b}$ \\
\hline Lubricant & $15.4^{\mathrm{b}}$ & $233.2^{\mathrm{b}}$ & $82.3^{\mathrm{b}}$ & $100.8^{\mathrm{b}}$ & $117.0^{\mathrm{b}}$ & $6.3^{\mathrm{a}}$ & $53.9^{\mathrm{b}}$ & $319.8^{\mathrm{b}}$ & $39.2^{\mathrm{b}}$ & $27.1^{\mathrm{b}}$ & $118.2^{\mathrm{b}}$ \\
\hline Length $\times$ MAPE & $2.9^{c}$ & $5.9^{\mathrm{a}}$ & $4.3^{\mathrm{a}}$ & $17.1^{\mathrm{b}}$ & $4.0^{\mathrm{a}}$ & $3.3^{\mathrm{a}}$ & $9.3^{b}$ & $10.7^{\mathrm{b}}$ & $2.8^{\mathrm{c}}$ & $4.3^{\mathrm{a}}$ & - \\
\hline Length $\times$ Lubricant & - & $0.5^{\mathrm{c}}$ & $0.3^{c}$ & $0.3^{c}$ & $3.1^{\mathrm{c}}$ & $5.4^{\mathrm{b}}$ & $0.9^{c}$ & $0.1^{\mathrm{c}}$ & - & $6.8^{\mathrm{b}}$ & $0.6^{\mathrm{c}}$ \\
\hline
\end{tabular}

$E$, Modulus of elasticity; $\sigma$, stress at rupture, and $\varepsilon$, strain at rupture.

a Significant at 0.05 significance level.

b Significant at 0.01 significance level.

${ }^{c}$ Not significant at 0.05 significance level.

increase the probability of voids within the composite. Nevertheless, the impact of fiber length on WPC density is low and should not have any significant practical implications.

The addition of $2 \%$ of MAPE in the composite formulation showed no significant impact on density (Table V). However, the addition of $4.5 \%$ OP-100 in the composite formulation had a significant impact on WPC density, characterized by a slight decrease. This decrease could be explained by the lower density of lubricant used in this study.

An example of density profile is presented in Figure 4, showing uniform WPC density. In agreement with previous findings, ${ }^{13}$ this result suggests that the two-step WPC formation produces a good dispersion of the wood fibers in the HDPE matrix. This result is important, because using fibers with high $L / D$ ratios without good fiber dispersion would not be practical. ${ }^{5}$ Processing WPC in two steps might be perceived as long and expensive. However, many industries prefer to produce a pelletized feedstock, which enables further processing by other techniques such as extrusion, injection, or compression molding. ${ }^{7}$

The impact of fiber length on water absorption and volumetric swelling of WPC was highly significant (Table V). In agreement with a previous report, ${ }^{22}$ water absorption increased with increasing particle size for the different immersion times tested

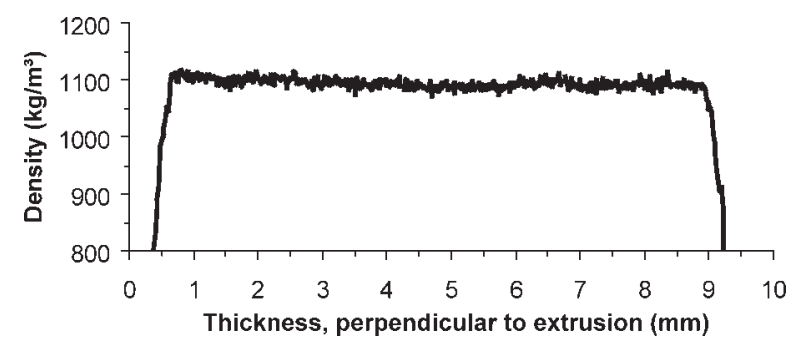

Figure 4 Typical density profile for a WPC made with CTMP fibers and HDPE.
(Fig. 5). Water absorption curves, plotted as a function of square root of time, are linear. By Fickian diffusion, the linearity of the curves suggests that no changes occurred in the diffusion mechanism (i.e., from cracking, damage, and/or capillary uptake). Water absorption for the WPC formulations using long fibers was up to $72 \%$ higher than those made with short fibers. Volumetric swelling showed a similar trend (Table IV). This is a basically undesirable effect and suggests that short fibers are more suitable for composites for use in moist environments. These short fibers might be coated with thin hydrophobic polymer film. The presence of voids in the long fibers within the composite represents water sites and results in higher water content in the composite after several hours of immersion in water.

Adding $2 \%$ of a coupling agent to the WPC resulted in a significant impact on water absorption and volumetric swelling (Table V). For all length classes, use of a coupling agent reduced water absorption (Table IV). This result is in agreement with the previous findings. ${ }^{22,23}$ Use of $4.5 \%$ lubricant in the WPC resulted in a significant impact on water absorption and volumetric swelling (Table V). For

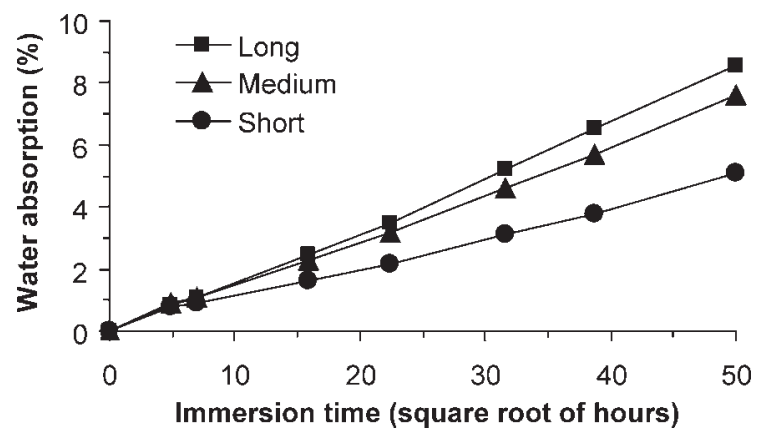

Figure 5 Variation of water absorption as a function of square root of immersion time for a WPC made with CTMP fibers of different lengths. 


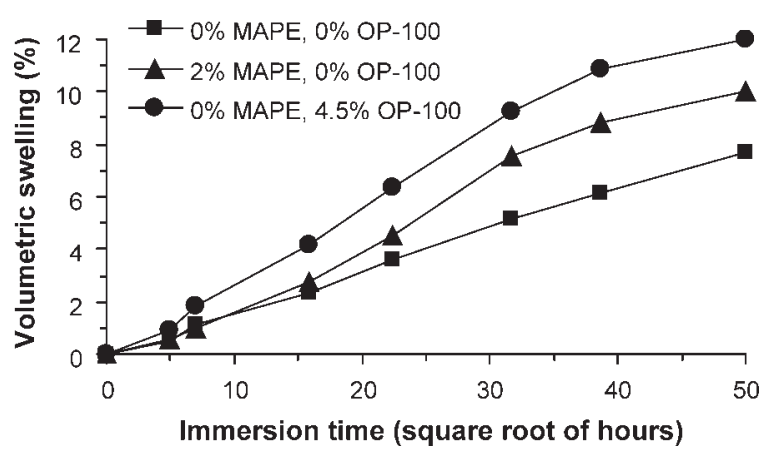

Figure 6 Variation of volumetric swelling as a function of square root of immersion time for a WPC made with CTMP fibers and different additives.

both properties, this impact is characterized by an increase (Table IV and Fig. 6).

The effect of fiber length was found to be highly significant on all mechanical properties measured in this study (Table V). Increasing fiber length had beneficial effects on tensile and flexural properties of the WPC made with HDPE and CTMP fibers (Table IV). This was true for both MOE and modulus of rupture (MOR). Maximum strain varied with increasing fiber length, albeit with minimal variation, and with no practical implications. Increasing fiber length also had a positive effect on toughness, as measured by both tensile rupture and Izod impact energy.

Examples of stress-strain curves in bending tests for the different fiber length classes are shown in Figure 7. A similar variation between the different lengths was found with the tensile tests (Table IV). Figure 8 shows the variation of the flexural and tensile MOE and MOR with increasing fiber length in HDPE.

These results indicate that the addition of wood fibers to HDPE considerably increased its MOE, but reduced its MOR (Fig. 8). These results are also in agreement with the previous findings. ${ }^{5}$ However, the decreased resistance could be minimized by increasing fiber length in the composite. When compared with the composites made with the short length class, flexural MOE improved up to $45 \%$, and tensile MOE improved up to $20 \%$ with increasing fiber length (Table IV). Flexural MOR improved by up to $39 \%$ and tensile MOR by up to $31 \%$. These results are also in agreement with the previous findings. ${ }^{6,9,10}$ In traditional wood-based composites, mechanical properties generally increase with increasing density. In this study, however, the opposite effect was observed, which suggests that the effect of fiber length on mechanical properties is dominant compared to the effect of density. According to the classical theory of mechanics, ${ }^{7,24}$ load applied to a fiber-reinforced composite material is transferred from matrix to fibers by shear stresses along the fiber-matrix interface. Transfer efficiency

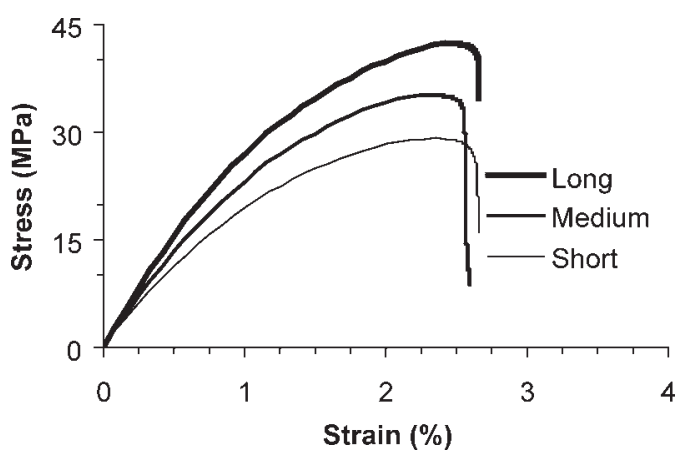

Figure 7 Typical stress strain curves in flexure for a WPC made with CTMP fibers of different lengths.

increases with increasing fiber $L / D$ ratio. Thus, the mechanical results observed in this study are in agreement with classical mechanics theory.

Composite toughness, measured by notched Izod impact and tensile strain energy, increased with increasing fiber length (Table IV). Results show that toughness increased up to $24 \%$ with increasing fiber length (Fig. 8).

In this study, use of MAPE resulted in lower tensile and flexure properties compared to formulations containing only wood and plastic. This effect is highly significant (Table V). This result has not yet been explained, and further investigations are needed to shed light on this issue. Among the hypotheses that could explain this unexpected outcome is the chemical modification of the fibrous structure in the pulping and bleaching processes of the CTMP fibers.

The use of OP-100 as a lubricant also resulted in lower tensile and flexure properties compared to the formulations containing only wood and plastic. This effect is highly significant (Table V) and is in agreement with a previous report. ${ }^{14}$ It is possible that the lubricant used interfered with the adhesion between matrix and fibers.

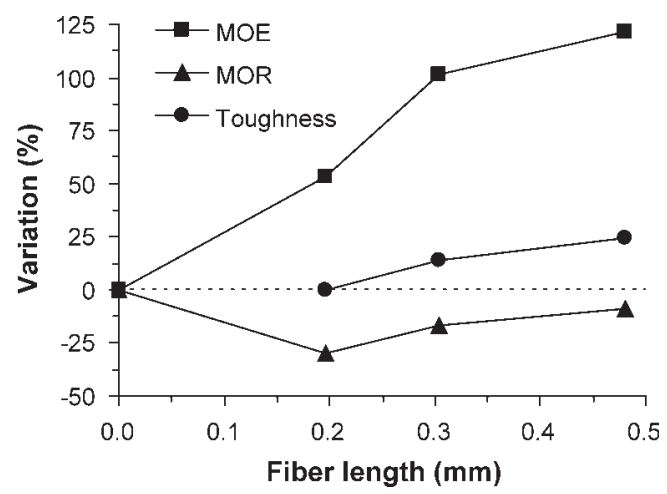

Figure 8 Variation of modulus of elasticity (MOE), modulus of rupture (MOR), and toughness for a WPC with increasing fiber length. 


\section{CONCLUSIONS}

This study investigated the effect of fiber length on melting properties, processing, and WPC properties. Rheometer torque properties increased with increasing fiber proportion and fiber length. Consequently, using different fiber lengths exerts an important impact on extrusion processing parameters. By using a two-stage extrusion process and adjusting processing parameters according to fiber size distribution, good quality WPC was produced with long fibers. Water absorption and volumetric swelling increased with fiber length. Increasing fiber length had beneficial effects on the tensile and flexural MOE and toughness of WPC. A decrease in the MOR was observed with the addition of wood fibers into the thermoplastic, but this effect could be minimized by using long fibers. Finally, the addition of both MAPE and lubricant decreased the mechanical properties of the WPC.

\section{References}

1. Smith, P. M.; Wolcott, M. P. Forest Prod J 2006, 56, 4.

2. Clemons, C. Forest Prod J 2002, 52, 10.

3. Saheb, D. N.; Jog, J. P. Adv Polym Tech 1999, 18, 351.

4. Wolcott, M. P. In Proceedings of the Non-Wood Substitutes for Solid Wood Products Conference, Melbourne, Australia, October 2003.

5. Wolcott, M. P.; Englund, K. A. In Proceedings of the 33rd International Particleboard and Composite Materials Symposium, Pullman, WA, April 12-15, 1999.
6. Stark, N. M.; Rowlands, R. E. Wood Fiber Sci 2003, 35, 167.

7. Gamstedt, K. E.; Nygård, P.; Lindström, M. In Proceedings of the 3rd Wood Fibre Polymer Composites International Symposium, Bordeaux, France, March 26-27, 2007.

8. Julson, J. L.; Subbarao, G.; Stokke, D. D.; Gieselman, H. H.; Muthukumarappan, K. J Appl Polym Sci 2004, 93, 2484.

9. Sanschagrin, B.; Sean, S. T.; Kokta, B. V. In Proceedings of the 43rd Annual Conference, Composites Institute, The Society of the Plastics Industry, Cincinnati, OH, February 1-5, 1988.

10. Lee, B. J.; McDonald, A. G.; James, B. Mater Res Innovat 2001, 4, 97.

11. Yam, K. L.; Gogoi, B. K.; Lai, C. C.; Selke, S. E. Polym Eng Sci 1990, 30, 693.

12. Wall, D. In Proceedings of the 45th Annual Technical Conference of Society of Plastic Engineers (ANTEC), Los Angeles, CA, May 1987.

13. Le Baillif M.; Oksman, K. In Proceedings of the Progress in Wood and Bio Fibre Plastic Composites Conference, Toronto, Canada, May 1-2, 2006.

14. Li, H.; Law, S.; Sain, M. J Reinf Plast Compos 2004, 23, 1153.

15. Shi, H.; Li, B.; Chen, C.; Jia, Y. J Appl Polym Sci 2007, 104, 3161.

16. Soucy, J.; Koubaa, A.; Erchiqui, F.; Englund, K.; Wolcott, M. P. In Proceedings of the 22nd Annual Meeting of the Polymer Processing Society Conference, Yamagata, Japan, July 2006.

17. Matuana, L. M.; Kim, J. J Vinyl Addit Technol 2007, 13, 7.

18. Schramm, G. A Practical Approach to Rheology and Rheometry; Gebrueder HAAKE GmbH: Karlsruhe, 1994.

19. Li, T. Q.; Wolcott, M. P. Polym Eng Sci 2005, 45, 549.

20. Soucy, J. Master's Thesis, Université du Québec à Chicoutimi, Canada, 2007.

21. Grande, C.; Torres, F. G. Adv Polym Tech 2003, 24, 145.

22. Steckel, V.; Clemons, C. M.; Thoemen, H. J Appl Polym Sci 2006, 103, 752.

23. Bledzki, A. K.; Faruk, O. Appl Compos Mater 2003, 10, 365.

24. Gibson, R. F. Principles of Composites Materials Mechanics; McGraw-Hill: New-York, NY, 1994. 